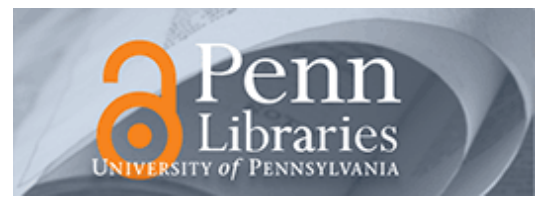

University of Pennsylvania

ScholarlyCommons

10-10-2013

\title{
Locally Delivered Salicylic Acid From a Poly(anhydride-ester): Impact on Diabetic Bone Regeneration
}

\author{
Keisuke Wada \\ University of Pennsylvania, wadak@dental.upenn.edu \\ Weling Yu \\ Mohamad Elaziz \\ University of Pennsylvania \\ Sandrine Barakat \\ University of Pennsylvania \\ Michelle A. Ouimet
}

See next page for additional authors

Follow this and additional works at: https://repository.upenn.edu/dental_papers

Part of the Endocrinology, Diabetes, and Metabolism Commons, and the Osteopathic Medicine and Osteopathy Commons

\section{Recommended Citation}

Wada, K., Yu, W., Elaziz, M., Barakat, S., Ouimet, M. A., Rosario-Meléndez, R., Fiorellini, J. P., Graves, D. T., \& Uhrich, K. E. (2013). Locally Delivered Salicylic Acid From a Poly(anhydride-ester): Impact on Diabetic Bone Regeneration. Journal of Controlled Release, 171 (1), 33-37. http://dx.doi.org/10.1016/ j.jconrel.2013.06.024

This paper is posted at ScholarlyCommons. https://repository.upenn.edu/dental_papers/24

For more information, please contact repository@pobox.upenn.edu. 


\title{
Locally Delivered Salicylic Acid From a Poly(anhydride-ester): Impact on Diabetic Bone Regeneration
}

\begin{abstract}
Diabetes mellitus (DM) involves metabolic changes that can impair bone repair, including a prolonged inflammatory response. A salicylic acid-based poly(anhydride-ester) (SA-PAE) provides controlled and sustained release of salicylic acid (SA) that locally resolves inflammation. This study investigates the effect of polymer-controlled SA release on bone regeneration in diabetic rats where enhanced inflammation is expected. Fifty-six Sprague-Dawley rats were randomly assigned to two groups: diabetic group induced by streptozotocin (STZ) injection or normoglycemic controls injected with citrate buffer alone. Three weeks after hyperglycemia development or vehicle injection, $5 \mathrm{~mm}$ critical sized defects were created at the rat mandibular angle and treated with SA-PAE/bone graft mixture or bone graft alone. Rats were euthanized 4 and 12 weeks after surgery, then bone fill percentage in the defect region was assessed by micro-computed tomography (CT) and histomorphometry. It was observed that bone fill increased significantly at 4 and 12 weeks in SA-PAE/bone graft-treated diabetic rats compared to diabetic rats receiving bone graft alone. Accelerated bone formation in normoglycemic rats caused by SA-PAE/ bone graft treatment was observed at 4 weeks but not at 12 weeks. This study shows that treatment with SA-PAE enhances bone regeneration in diabetic rats and accelerates bone regeneration in normoglycemic animals.
\end{abstract}

\section{Keywords}

poly(anhydride-ester, salicylic acid, diabetes, bone regeneration

\section{Disciplines}

Endocrinology, Diabetes, and Metabolism I Osteopathic Medicine and Osteopathy

\section{Author(s)}

Keisuke Wada, Weling Yu, Mohamad Elaziz, Sandrine Barakat, Michelle A. Ouimet, Roselin RosarioMeléndez, Joseph P. Fiorellini, Dana T. Graves, and Kathryn E. Uhrich 


\title{
Locally Delivered Salicylic Acid from a Poly(anhydride-ester): Impact on Diabetic Bone Regeneration
}

\author{
Keisuke Wada ${ }^{a}$, Weiling Yu ${ }^{b,{ }^{*},}$ Mohamad Elazizia ${ }^{a}{ }^{\star}$, Sandrine Barakat ${ }^{a},{ }^{,}$, Michelle A. \\ Ouimet $^{\mathrm{c}}$, Roselin Rosario-Meléndez ${ }^{\mathrm{c}}$, Joseph P. Fiorellini ${ }^{\mathrm{a}}$, Dana T. Graves ${ }^{\mathrm{a}}$, and Kathryn \\ E. Uhrich ${ }^{\mathrm{b}, \mathrm{c},+}$ \\ aDepartment of Periodontics, University of Pennsylvania School of Dental Medicine, 240 South \\ $40^{\text {th }}$ Street, Philadelphia, PA 19104, United States \\ bDepartment of Biomedical Engineering, Rutgers, The State University of New Jersey, 599 Taylor \\ Road, Piscataway, NJ 08854, United States \\ 'Department of Chemistry and Chemical Biology, Rutgers, The State University of New Jersey, \\ 610 Taylor Road, Piscataway, NJ 08854, United States
}

\begin{abstract}
Diabetes mellitus (DM) involves metabolic changes that can impair bone repair, including a prolonged inflammatory response. A salicylic acid-based poly(anhydride-ester) (SA-PAE) provides controlled and sustained release of salicylic acid (SA) that locally resolves inflammation. This study investigates the effect of polymer-controlled SA release on bone regeneration in diabetic rats where enhanced inflammation is expected. Fifty-six Sprague-Dawley rats were randomly assigned to two groups: diabetic group induced by streptozotocin (STZ) injection or normoglycemic controls injected with citrate buffer alone. Three weeks after hyperglycemia development or vehicle injection, $5 \mathrm{~mm}$ critical sized defects were created at the rat mandibular angle and treated with SA-PAE/bone graft mixture or bone graft alone. Rats were euthanized 4 and 12 weeks after surgery, then bone fill percentage in the defect region was assessed by microcomputed tomography (CT) and histomorphometry. It was observed that bone fill increased significantly at 4 and 12 weeks in SA-PAE/bone graft-treated diabetic rats compared to diabetic rats receiving bone graft alone. Accelerated bone formation in normoglycemic rats caused by SAPAE/bone graft treatment was observed at 4 weeks but not at 12 weeks. This study shows that treatment with SA-PAE enhances bone regeneration in diabetic rats and accelerates bone regeneration in normoglycemic animals.
\end{abstract}

\section{Keywords}

poly(anhydride-ester); salicylic acid; diabetes; bone regeneration

\footnotetext{
(C) 2013 Elsevier B.V. All rights reserved.

${ }^{+}$Corresponding author: Dr. Kathryn E. Uhrich, Department of Chemistry and Chemical Biology, Rutgers, The State University of New Jersey, 610 Taylor Road, Piscataway, NJ 08854, United States, Tel.: +1 7324450361 , keuhrich@ rutgers.edu.

* These authors contributed equally to this work.

Publisher's Disclaimer: This is a PDF file of an unedited manuscript that has been accepted for publication. As a service to our customers we are providing this early version of the manuscript. The manuscript will undergo copyediting, typesetting, and review of the resulting proof before it is published in its final citable form. Please note that during the production process errors may be discovered which could affect the content, and all legal disclaimers that apply to the journal pertain.
} 


\section{Introduction}

Diabetes mellitus (DM) is a common metabolic disorder associated with hyperglycemia and hyperlipidemia due to lack of insulin or insulin resistance and affecting $8.3 \%$ of the U.S. population in 2011 [1]. DM has been shown to increase systemic inflammation and prolong inflammatory response to injury [2]. Specifically, DM enhances inflammation through the formation of reactive oxygen species, advanced glycation endproducts, hypoinsulinemia, and/or insulin resistance [3].

Type 1 diabetes causes osteopenia, and both type- 1 and type- 2 diabetes have been linked to poor bone quality and reduced capacity to form bone [4-5]. Factors contributing to this deficit include decreased transcription factor expression needed to regenerate bone [6], inflammation [7], and diminished vascularity [8]. Furthermore, diabetes-enhanced inflammation has been linked to prolonged osteoclastogenesis that may reduce bone quality [9-11].

Bone grafting is often used to treat orthopedic and oral-facial defects [12-13]. In DM, however, bone regeneration procedures result in a greater degree of variability and increased infection rates [14-15]. Growth factors have been extensively studied and found to be beneficial for bone regeneration in humans [16-17]. However, they are extremely expensive and some still have unresolved safety concerns (e.g., high complication rates and potential carcinogenicity of bone morphogenetic proteins (BMPs) in human [18-19]). As a result, exploring new methods to improve bone regeneration is necessary, especially in diabetic subjects whose bone regeneration capability is compromised by long term diabetesenhanced inflammation.

Salicylic acid-based poly(anhydride-esters) (SA-PAE) have been synthesized by chemically incorporating salicylic acid (SA) within a polyanhydride [20]. SA-PAEs degrade via hydrolysis of anhydride and ester bonds and release SA and a biocompatible molecule, in our case adipic acid (Figure 1) [21-22]. SA is an anti-inflammatory that reduces the production of pro-inflammatory cytokines such as prostaglandins, TNF-a, IL-1, and IL-6 [23]. Several studies have shown that elevation of these cytokines impairs bone healing by affecting the activity and survival of osteoblasts and osteoclasts [24-27]. Therefore, SAPAEs could potentially improve bone regeneration through mediation of inflammation.

In this study, the influence of localized, sustained delivery of SA on bone regeneration in diabetic and normoglycemic rats was evaluated. Our results indicate that SA delivered by an SA-PAE significantly promotes new bone formation in diabetic rats and accelerates new bone formation in normoglycemic rats.

\section{Material and Methods}

\subsection{Sample Preparation}

The SA-PAE was synthesized using previously reported methods [28]. The polymer was ground into a fine powder and physically mixed with freeze-dried bone allograft (LifeNet Health ${ }^{\circledR}$, Virginia Beach, VA) at a 1:1 weight ratio (7.5 mg of SA-PAE mixed with $7.5 \mathrm{mg}$ of bone graft). Approximately $40 \mu \mathrm{L}$ light mineral oil (Sigma-Aldrich, Milwaukee) was added to the mixture, which was then sterilized under ultra-violet light in a Spectrolinker XL-1500 UV Crosslinker (Spectronics Corporation, Westbury, NY) at $\lambda=254 \mathrm{~nm}$ and $5,500-6,500 \mu \mathrm{W} / \mathrm{cm}^{2}$ for $900 \mathrm{~s}$. Control samples were prepared without SA-PAE and treated identically to the SA-PAE-containing samples. 


\subsection{In Vitro SA-PAE/Bone Graft}

The SA release from samples prepared in section 2.1 was evaluated in vitro using phosphate buffered saline (PBS) (Sigma-Aldrich, Milwaukee). PBS pH was adjusted to 7.4 using $1 \mathrm{~N}$ sodium hydroxide. All pH measurements were performed using an Accumet ${ }^{\circledR}$ AR15 pH meter (Fisher Scientific, Fair Lawn, NJ). To measure SA release, $15 \mathrm{mg}$ of sterilized samples $(\mathrm{n}=3)$ were placed in $20 \mathrm{~mL}$ Wheaton glass scintillation vials with $10 \mathrm{~mL}$ of PBS and incubated at $37{ }^{\circ} \mathrm{C}$ with agitation at $60 \mathrm{rpm}$ using a controlled environment incubatorshaker (New Brunswick Scientific Co., Edison, NJ) to mimic physiological conditions. The buffer solution was replaced with fresh PBS $(10 \mathrm{~mL})$ every 24 hours and analyzed over 21 days. Spent media was analyzed by UV spectrophotometry using a Perkin Elmer Lambda XLS spectrophotometer (Waltham, MA) to specifically monitor SA release. Measurements were obtained at $\lambda=303 \mathrm{~nm}$, the maximum absorbance of SA that does not overlap with other polymer degradation products. Data were calculated against a calibration curve of absorbance values from standard solutions of known SA concentrations in PBS.

\subsection{Animal Model}

Animal care and surgical procedures were approved by the IACUC of the University of Pennsylvania. Fifty-six adult male Sprague-Dawley rats weighing $250 \mathrm{~g}-350 \mathrm{~g}$ were used, $\mathrm{n}=7$ per group. The rats were randomly divided into diabetic and normoglycemic groups. Diabetes was induced by intraperitoneal injection of streptozotocin, $70 \mathrm{mg} / \mathrm{kg}$ (SigmaAldrich, Milwaukee, WI). Blood glucose was monitored by the glucose-oxidase method (Glucometer Encore, Miles, Elkhart, IN) and HbA1c was measured at the time of euthanasia (Table 1). A blood glucose level greater than $250 \mathrm{mg} / \mathrm{dL}$ was considered diabetic. Animals were monitored for 3 weeks to confirm their diabetic status and to evaluate their daily food intake, activity, weight, and overall health. Of the 56 rats that underwent surgery, two died during the procedure; no significant reductions in body weight occurred and 3 postoperative infections were observed in the diabetic group.

2.3.1. Surgical Procedure-All procedures were performed under general anesthesia with an intraperitoneal injection of ketamine, $75 \mathrm{mg} / \mathrm{kg}$ (Fort Dodge Laboratories, Fort Dodge, IA) and xylazine, $5 \mathrm{mg} / \mathrm{kg}$ (Miles Inc., Shawnee Mission, KS). Surgical procedures were performed under sterile conditions. A 15 to $20 \mathrm{~mm}$ incision was made on the lateral aspect of the mandible. A $5 \mathrm{~mm}$ diameter osteotomy defect was created at the angle of the mandible using a trephine burr with sterile saline irrigation. The site was grafted with SAPAE/bone graft mixture or bone graft alone, as prepared in section 2.1. A BioGuide ${ }^{\circledR}$ resorbable collagen membrane (Geistlich Pharma., North America Inc., NJ) was adapted to circumferentially cover the defect. The surgical field was closed in layers, a muscular layer and the external skin layer, using Chromic gut 5-0 resorbable sutures (Ethicon, Somerville, $\mathrm{NJ})$. A single dose of buprenorphine $(0.05 \mathrm{mg} / \mathrm{kg})$ was administered for postoperative pain relief. Rats were euthanized at 4 and 12 weeks. The mandibles were dissected and fixed in 4\% phosphate buffered formalin solution for 24 hours and then stored in PBS until microcomputed tomography (micro-CT) scans were performed.

\subsection{Micro-Computed Tomography}

Micro-CT images were obtained using a eXplore Locus SP micro-CT scanner (GE Healthcare, Pittsburgh, PA). Images were taken at a resolution of $48 \mu \mathrm{m}$. The micro-CT data sets were reconstructed with the GEHC eXplore Scan Control (GE Healthcare, Pittsburgh, PA) and evaluated by OsiriX 64 image analysis software (Pixmeo, Geneva, Switzerland). The original circular defect was located, and a 3-D region-of-interest (ROI) measuring 5.0 $\mathrm{mm}$ in diameter and $0.3 \mathrm{~mm}$ in height was established for the original defect. A bone/nobone threshold value in CT Hounsfield units (HU) was determined and used to measure the 
mineralized bone (new bone and bone graft) present in the osteotomy defect. For each specimen, new bone formation was expressed as a percentage of mineralized bone in the 5.0 mm diameter defect. The number of samples per group was 6 to 7 .

\subsection{Histologic Analysis}

After micro-CT scan, specimens were demineralized with 10\% EDTA (Fisher scientific USA, Pittsburgh, PA), which was changed three times per week for 7 weeks. The specimen was cut in half after decalcification, embedded in paraffin and sectioned at the midline of the defect. $5 \mu \mathrm{m}$ thickness histologic sections were prepared and stained with hematoxylin and eosin. Histologic analysis was performed using NIS Elements software (Nikon, Melville, NY) and the percentage of new bone in the defect area was assessed. One half of the defect was analyzed and the percentage of new bone formation was calculated by dividing the area of new bone within the defect on one side by the total area of that side ( $2.5 \mathrm{~mm}$ in length). Some samples were lost due to technical reasons. The number of samples per group was 3 to 4.

\subsection{Statistical Analyses}

Data are presented as mean \pm standard deviation $(\mathrm{SD})$ or mean $+\mathrm{SD}$. The difference between diabetic and normoglycemic groups at each time point was analyzed by Student's ttest. Significance was determined at $\mathrm{p}<0.05$.

\section{Results}

\subsection{In Vitro SA Release from SA}

The formulation described herein includes bone graft, mineral oil and SA-PAE. To test whether the addition of bone graft and mineral oil influenced SA release rates, an in vitro study was performed in PBS over 21 days using this new formulation and analyzed by UV spectrophotometry to ascertain the release profile. The normalized, cumulative SA release curves (Figure 2), demonstrates that SA was released after a lag period of minimal to no SA (2 days). Near zero-order release, common for polyanhydrides and poly(anhydride-esters) due to their surface-eroding behavior [29-30], was observed from days 3-13. These results demonstrate that this new formulation sustained SA release over 16 days.

\subsection{Bone Fill of Osteotomy Defect}

The amount of mineralized bone (new bone and bone graft) in the osteotomy defect was measured by micro-CT (Figure 3). At the 4-week time point (Figure 4), SA-PAE/bone grafttreated rats had significantly higher bone fill percentage than the control rats (bone graft only) ( $\mathrm{p}<0.05$ ). Specifically, diabetic rats treated with SA-PAE/bone graft had $44 \%$ more bone fill than diabetic control rats (bone graft only), and normoglycemic rats treated with SA-PAE/bone graft had $37 \%$ more bone fill than normoglycemic control rats (bone graft only).

At 12 weeks (Figure 4), diabetic rats treated with SA-PAE/bone graft had $43 \%$ more bone fill than the diabetic control rats (bone graft alone) $(\mathrm{p}<0.05)$. No significant difference in bone fill percentage was observed between normoglycemic rats receiving SA-PAE/bone graft and the controls (bone graft alone) ( $p>0.05)$. The percentage of bone fill normoglycemic control group was $32 \%$ greater than the diabetic control group ( $p<0.05)$. However, no significant difference in bone fill percentage was observed between the SA$\mathrm{PAE} /$ bone graft-treated group and the control group in normoglycemic rats. 


\subsection{Histologic Analysis}

Results from histologic analysis at 12 weeks agree with the micro-CT results (Figure 5 and 6). Treatment of diabetic rats with SA-PAE/bone graft resulted in $115 \%$ more bone fill than diabetic control rats $(\mathrm{p}<0.05)$, whereas treating normoglycemic rats with SA-PAE/bone graft did not increase bone fill significantly $(\mathrm{p}>0.05)$. In additon, bone fill percentage in the normoglycemic control group was $101 \%$ greater than the diabetic control group ( $p>0.05)$.

\section{Discussion}

Our results demonstrate the positive effect of localized, controlled, and sustained SA release on bone regeneration in both diabetic and normoglycemic rats. It significantly enhanced bone regeneration of diabetic rats at 4 and 12 weeks and normoglycemic rats at 4 weeks (Figure 4,6). One explanation for this positive result centers on the sustained SA release from SA-PAE; SA suppresses nuclear factor kappa-light-chain-enhancer of activated B cells (NF-kB) activation and thus reduces the production of pro-inflammatory cytokines, such as IL-1, IL-6, and TNF-a [31]. These cytokines have been reported to reduce bone formation and enhance bone resorption so their down-regulation by SA would favor bone regeneration [32]. Further, the SA COX inhibiting effect reduces prostaglandin production, which could reduce bone resorption [33-35]. Yet, other studies have also reported that prostaglandin can increase bone formation [36]. The mechanism determining the anabolic or catabolic effect of prostaglandin on bone formation is still unknown [37].

Another explanation for SA-PAE enhanced bone formation is the controlled SA release from SA-PAE; specifically, a lag period followed by sustained SA release. The lag period (i.e., minimum-to-no SA release) allows the initial inflammatory response to develop, which is necessary for subsequent bone healing to occur [38]. After the lag period, sustained SA release resolves prolonged inflammation and thus favors bone regeneration, as suggested by previous studies [39-40]. Our results show that the SA-PAE has greater effects on diabetic rats than normoglycemic rats at the 12 -week time point. This is potentially due to the diabetes-enhanced long-term inflammation that impairs bone regeneration, which agrees with the significantly lower bone regeneration in diabetic rats compared to normoglycemic rats at 12 weeks (Figure 4,6). Therefore, the SA anti-inflammatory effects could lead to a greater difference between the experimental group and the controls in diabetic rats.

Our results agree with previous work where SA-PAEs increased bone formation in vivo in normoglycemic animals [40]. A previous study using a localized SA-PAE implantation, however, did not increase bone formation [41]. The difference is potentially due to a much lower SA-PAE dosing used herein (about 17 times less SA-PAE compared to the previous study) and different formulation (i.e. combining SA-PAE with bone graft and mineral oil). These factors may render a higher level of initial inflammation that is desirable for subsequent healing. Compared to other studies evaluating nonsteroidal anti-inflammatory drugs (NSAIDs) effects on bone regeneration, whose results suggest that NSAIDs do not favor bone regeneration [42], our results show a positive effect of SA. The difference in findings is likely caused by our unique drug delivery system that releases SA in a localized, controlled, and sustained manner. Another factor contributing to the positive SA-PAE effect observed is the diabetic condition of animals, for which anti-inflammatory treatments are expected to be more beneficial due to the long-term diabetes-enhanced inflammation.

\section{Conclusion}

Treatment with SA-PAE/bone graft enhances bone regeneration in diabetic rats and accelerates bone regeneration in normoglycemic animals. This study is the first time that an SA-PAE has been applied to diabetic animals for bone regeneration purposes; our results 
suggest that a mixture of SA-PAE/bone graft is very effective on diabetic bone healing. In addition to the advantages of localized, controlled and sustained SA release, our polymer system enables the incorporation of other bioactives (such as insulin) to further improve bone regeneration. Future studies will focus on the mechanism of SA-PAE-enhanced diabetic bone regeneration and incorporating other bioactives into the polymer matrix to improve system performance.

\section{Acknowledgments}

This work was funded by a grant from the NIDCR DE013207. Contributions from Dr. Bryan Langowski, and Mohammad Alqatani are gratefully acknowledged.

\section{References}

1. American Diabetes Association. Diabetes Facts Sheet. 2011

2. Graves DT, Kayal RA. Diabetic complications and dysregulated innate immunity. Front Biosci. 2008; 13:1227-1239. [PubMed: 17981625]

3. Ponugoti B, Dong G, Graves DT. Role of forkhead transcription factors in diabetes-induced oxidative stress. Exp Diabetes Res. 2012:939751. [PubMed: 22454632]

4. Adami S. Bone health in diabetes: considerations for clinical management. Curr. Med. Res. Opin. 2009; 25:1057-1072. [PubMed: 19292601]

5. Claes L, Recknagel S, Ignatius A. Fracture healing under healthy and inflammatory conditions. Nat. Rev. Rheumatol. 2012; 8:133-143. [PubMed: 22293759]

6. Lu H, Kraut D, Gerstenfeld L, Graves DT. Diabetes interferes with the bone formation by affecting the expression of transcription factors that regulate osteoblast differentiation. Endocrinology. 2003; 144:346-352. [PubMed: 12488363]

7. Pacios S, Kang J, Galicia J, Gluck K, Patel H, Ovaydi-Mandel A, Petrov S, Alawi F, Graves DT. Diabetes aggravates periodontitis by limiting repair through enhanced inflammation. FASEB. 2012; 26:1423-1430.

8. Sasso FC, Torella D, Carbonara O, Ellison GM, Torella M, Scardone M, Marra C, Nasti R, Marfella R, Cozzolino D, Indolfi C, Cotrufo M, Torella R, Salvatore T. Increased vascular endothelial growth factor expression but impaired vascular endothelial growth factor receptor signaling in the myocardium of type 2 diabetic patients with chronic coronary heart disease. J. Am. Coll. Cardiol. 2005; 46:827-834. [PubMed: 16139132]

9. Hie M, Tsukamoto I. Increased expression of the receptor for activation of NF-kappaB and decreased runt-related transcription factor 2 expression in bone of rats with streptozotocin-induced diabetes. Int. J. Mol. Med. 2010; 26:611-618. [PubMed: 20818503]

10. Kayal RA, Tsatsas D, Bauer MA, Allen B, Al-Sebaei MO, Kakar S, Leone CW, Morgan EF, Gerstenfeld LC, Einhorn TA, Graves DT. Diminished bone formation during diabetic fracture healing is related to the premature resorption of cartilage associated with increased osteoclast activity. J. Bone. Miner. Res. 2007; 22:560-568. [PubMed: 17243865]

11. Liu R, Bal H, Desta T, Krothapalli N, Alyassi M, Luan Q, Graves DT. Diabetes enhances periodontal bone loss through enhanced resorption and diminished bone formation. J. Dent. Res. 2006; 85:510-514. [PubMed: 16723646]

12. Dinopoulos H, Dimitriou R, Giannoudis PV. Bone graft substitutes: What are the options? Surgeon. 2012; 10:230-239. [PubMed: 22682580]

13. Semb G. Alveolar bone grafting. Front. Oral Biol. 2012; 169:124-136. [PubMed: 22759676]

14. Retzepi M, Lewis MP, Donos N. Effect of diabetes and metabolic control on de novo bone formation following guided bone regeneration. Clin. Oral. Impl. Res. 2010; 21:71-79.

15. Ramanujam CL, Facaros Z, Zgonis T. An overview of bone grafting techniques for the diabetic charcot foot and ankle. Clin. Podiatr. Med. Surg. 2012; 29:589-595. [PubMed: 23044065]

16. White AP, Vaccaro AR, Hall JA, Whang PG, Friel BC, McKee MD. Clinical applications of BMP-7/OP-1 in fractures, nonunions and spinal fusion. Int Orthop. 2007; 31:735-741. [PubMed: 17962946] 
17. Fiorellini JP, Howell TH, Cochran D, Malmquist J, Lilly LC, Spagnoli D, Toljanic J, Jones A, Nevins M. Randomized study evaluating recombinant human bone morphogenetic protein-2 for extraction socket augmentation. J. Periodont. 2005; 76:605-613. [PubMed: 15857102]

18. Govender PV, Rampersaud YR, Rickards L, Fehlings MG. Use of osteogenic protein-1 in spinal fusion: literature review and preliminary results in a prospective series of high-risk cases. Neurosurg. Focus. 2002; 13

19. Garrison KR, Donell S, Ryder J, Shemilt I, Mugford M, Harvey I, Song F. Clinical effectiveness and cost-effectiveness of bone morphogenetic proteins in the non-healing of fractures and spinal fusion: a systematic review. Health Technol Assess. 2007; 11:1-150. [PubMed: 17669279]

20. Erdmann L, Uhrich KE. Synthesis and degradation characteristics of salicylic acid-derived poly(anhydride-esters). Biomaterials. 2000; 21:1941-1946. [PubMed: 10941915]

21. Schmeltzer RC, Schmalenberg KE, Uhrich KE. Synthesis and cytotoxicity of salicylate-based poly(anhydride esters). Biomacromolecules. 2005; 6:359-367. [PubMed: 15638540]

22. Erdmann L, Macedo B, Uhrich KE. Degradable poly(anhydride ester) implants: effects of localized salicylic acid release on bone. Biomaterials. 2000; 21:2507-2512. [PubMed: 11071600]

23. Housby JN, Cahil CM, Chu B, Prevelige R, Bickford K, Stevenson MA, Calderwood SK. Nonsteroidal anti-inflammatory drugs inhibit the expression of cytokines and induce HSP70 in human monocytes. Cytokine. 1999; 11:347-358. [PubMed: 10328874]

24. Fujita D, Yamashita N, Iita S, Amano H, Yamada S, Sakamoto K. Prostaglandin E2 induced the differentiation of osteoclasts in mouse osteoblast-depleted bone marrow cells. Prostaglandins Leukot Essent Fatty Acids. 2003; 68:351-358. [PubMed: 12711253]

25. Gruber R, Karreth F, Fischer MB, Watzek G. Platelet-released supernatants stimulate formation of osteoclast-like cells through a prostaglandin/RANKL-dependent mechanism. Bone. 2002; 30:726732. [PubMed: 11996911]

26. Lader C, Flanagan A. Prostaglandin E2, interleukin 1 alpha, and tumor necrosis factor-alpha increase human osteoclast formation and bone resorption in vitro. Endocrinology. 1998; 139:3157-3164. [PubMed: 9645689]

27. Okada Y, Lorenzo JA, Freeman AM, Tomita M, Morham SG, Raisz LG, Pilbeam CC. Prostaglandin G/H synthase-2 is required for maximal formation of osteoclast-like cells in culture. J. Clin. Invest. 2000; 105:823-832. [PubMed: 10727451]

28. Schmeltzer RC, Anastasiou TJ, Uhrich KE. Optimized synthesis of salicyliate-based poly(anhydride-esters). Polymer Bulletin. 2003; 49:441-448. [PubMed: 23976808]

29. Whitaker-Brothers K, Uhrich KE. Investigation into the erosion mechanism of salicylate-based poly(anhydride-esters). J. Biomed. Mater. Res. A. 2006; 76:470-479. [PubMed: 16315189]

30. Göpferich A, Tessmar J. Polyanhydride degradation and erosion. Adv. Drug. Deliv. Rev. 2006; 54:911-931. [PubMed: 12384315]

31. Khan A, Wilson U. Reactive oxygen species as cellular messengers. Current Biology. 1995; 2:437-445.

32. Dimitriou R, Tsiridis E, Giannoudis PV. Current concepts of molecular aspects of bone healing. International Journal of the Care of the Injured. 2005; 36:1392-1404. [PubMed: 16102764]

33. Vane J, Botting R. Inflammation and the mechanism of action of anti-inflammatory drugs. The Journal of Federation of American Societies for Experimental Biology. 1987; 1:89-96.

34. Suzawa T, Miyaura C, Inada M, Maruyama T, Sugimoty Y, Ushikubi R, Ichikawa A, Narumiya S, Suda T. The role of prostaglandin E receptor subtypes (EP1, EP2, EP3, and EP4) in bone resorption: an analysis using specific agonists for the respective EPs. Endocrinology. 2000; 141:1554-1559. [PubMed: 10746663]

35. Morinaga Y, Fujita N, Ohishi K, Zhang Y, Tsuruo T. Suppression of interleukin-11-mediated bone resorption by cyclooxygenases inhibitors. Journal of Cellular Physiology. 1998; 175:247-254. [PubMed: 9572469]

36. Jee WSS, Ma RF. The in vivo anabolic actions of prostaglandins in bone. Bone. 1997; 21:297-304. [PubMed: 9315332]

37. Blackwell KA, Raisz LG, Pilbeam CC. Prostaglandins in bone: bad cop, good cop? Trends in Endocrinology and Metabolism. 2010; 21:294-301. [PubMed: 20079660]

38. Simmons DJ. Fracture healing perspectives. Clin Orthop. 1985; 200:100-113. [PubMed: 3905103] 
39. Reynolds MA, Prudencio A, Aichelmann-Reidy ME, Woodward K, Uhrich KE. Non-steroidal anti-inflammatory drug (NSAID)-derived poly(anhydride-esters) in bone ad periodontal regeneration. Current Drug Delivery. 2007; 4:233-239. [PubMed: 17627497]

40. Erdmann L, Macedo B, Uhrich KE. Degradable poly(anhydride ester) implants: effects of localized salicylic acid release on bone. Biomaterials. 2000; 21:2507-2512. [PubMed: 11071600]

41. Harten RD, Svach DJ, Schmeltzer R, Uhrich KE. Salicylic acid-derived poly(anhydride-esters) inhibit bone resorption and formation in vivo. Journal of Biomedical Materials Research. 2005; 72A:354-362. [PubMed: 15678485]

42. Cottrell J, O'Connor JP. Effect of non-steroidal anti-inflammatory drugs on bone healing. Pharmaceuticals. 2010; 3:1668-1693. 


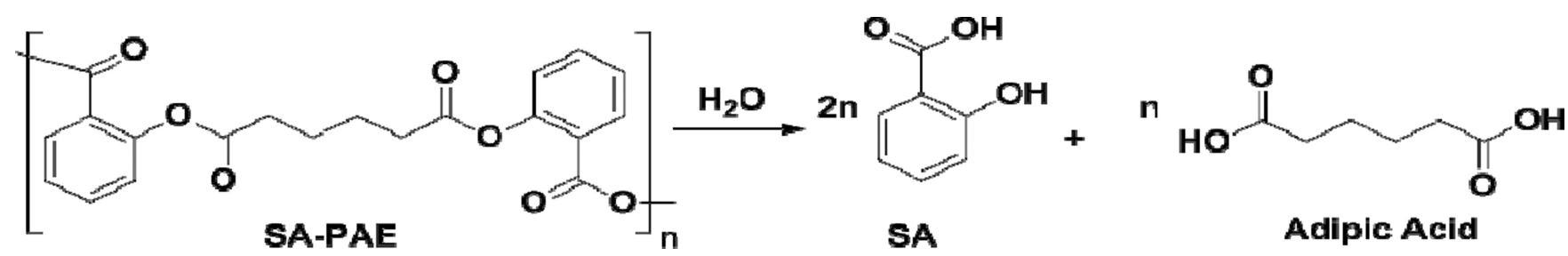

Figure 1.

SA-PAE degradation releases SA and adipic acid upon anhydride and ester bond hydrolysis. 


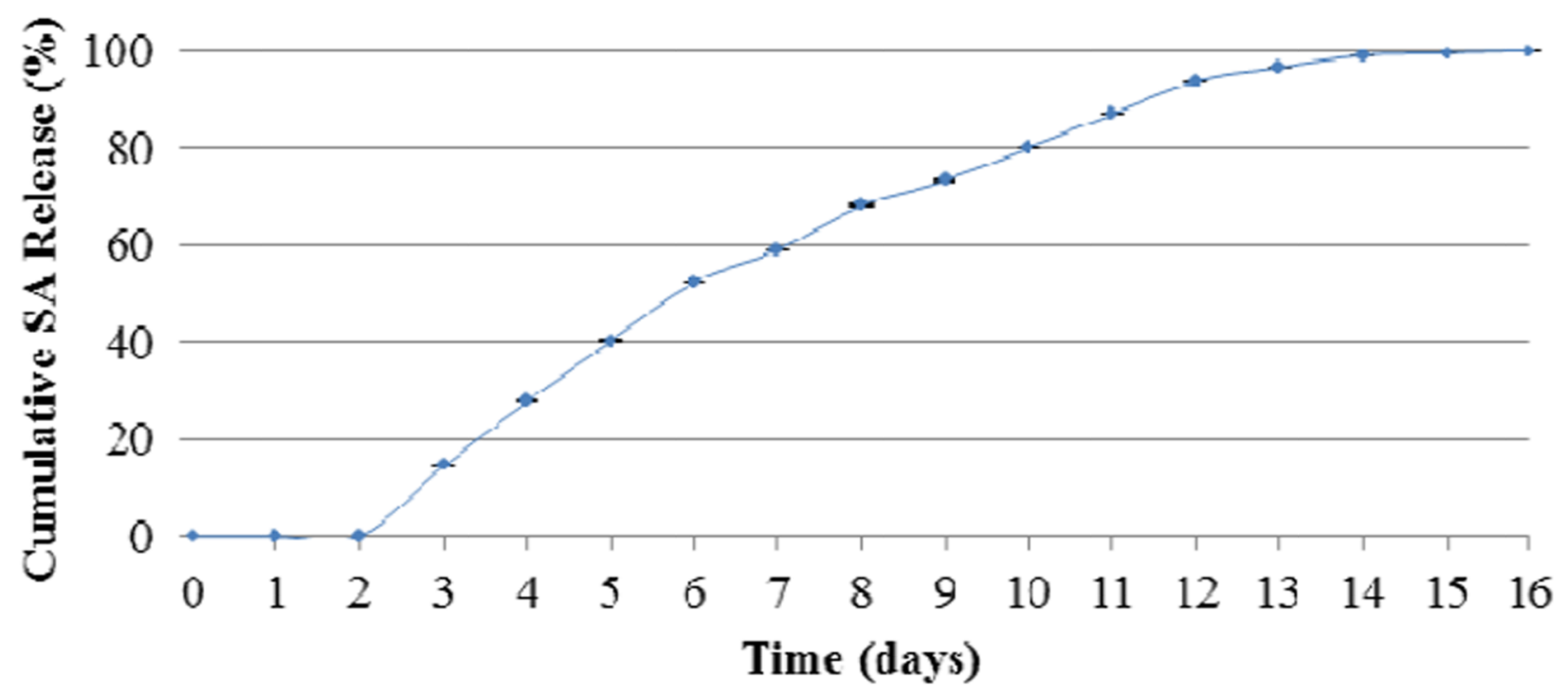

Figure 2.

In vitro $\mathrm{SA}$ release from formulated samples (mean \pm standard deviation) over 16 days 

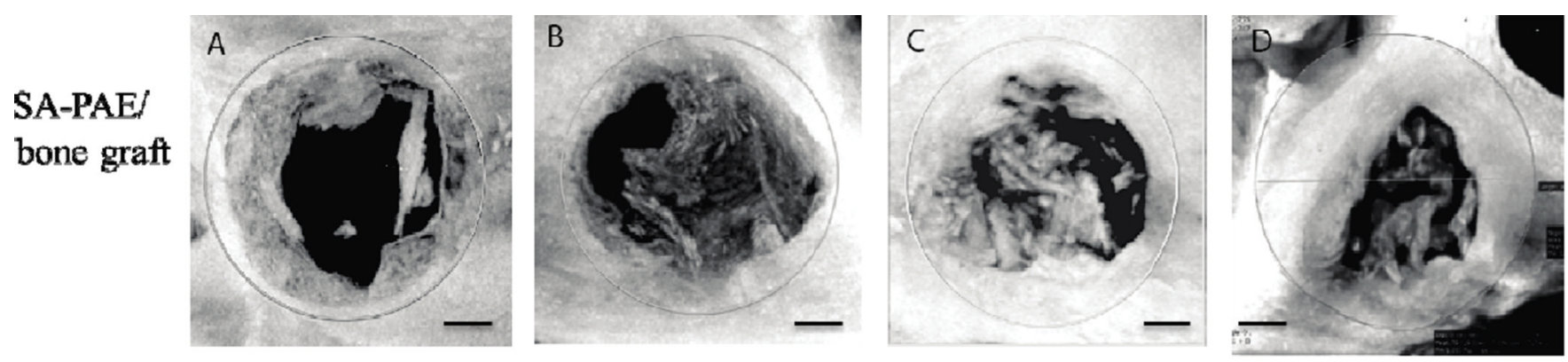

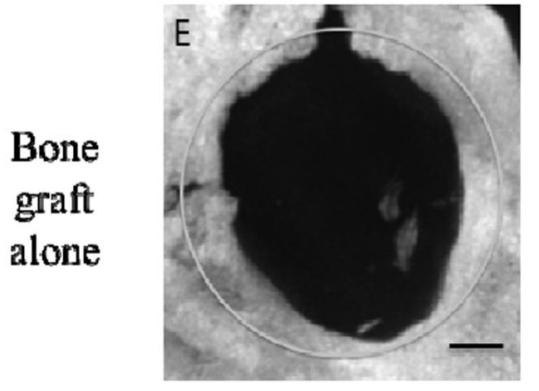

Diabetic

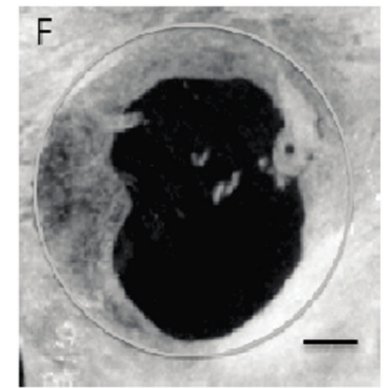

Normoglycemic

4 weeks

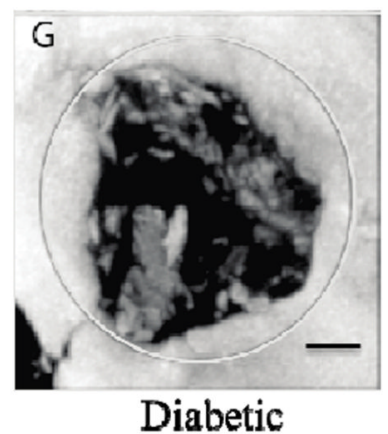

Diabetic

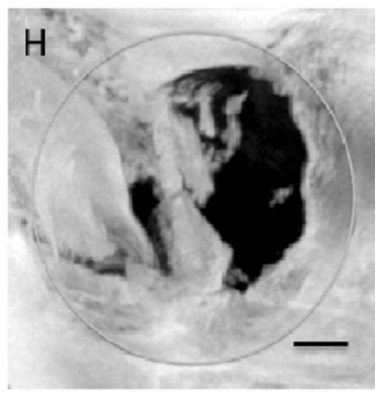

Normoglycemic

12 weeks

Figure 3.

Representative micro-CT images of mineralized bone formation in defect region (gray circle). Diabetic (A, C, E, G) and normoglycemic (B, D, F, H) rats were implanted with SAPAE/bone graft (A, B, C, D) or bone graft alone $(\mathrm{E}, \mathrm{F}, \mathrm{G}, \mathrm{H})$ in the $5 \mathrm{~mm}$ diameter critical size defect. $\mathrm{N}=6-7 /$ group. $\mathrm{Bar}=1 \mathrm{~mm}$. 


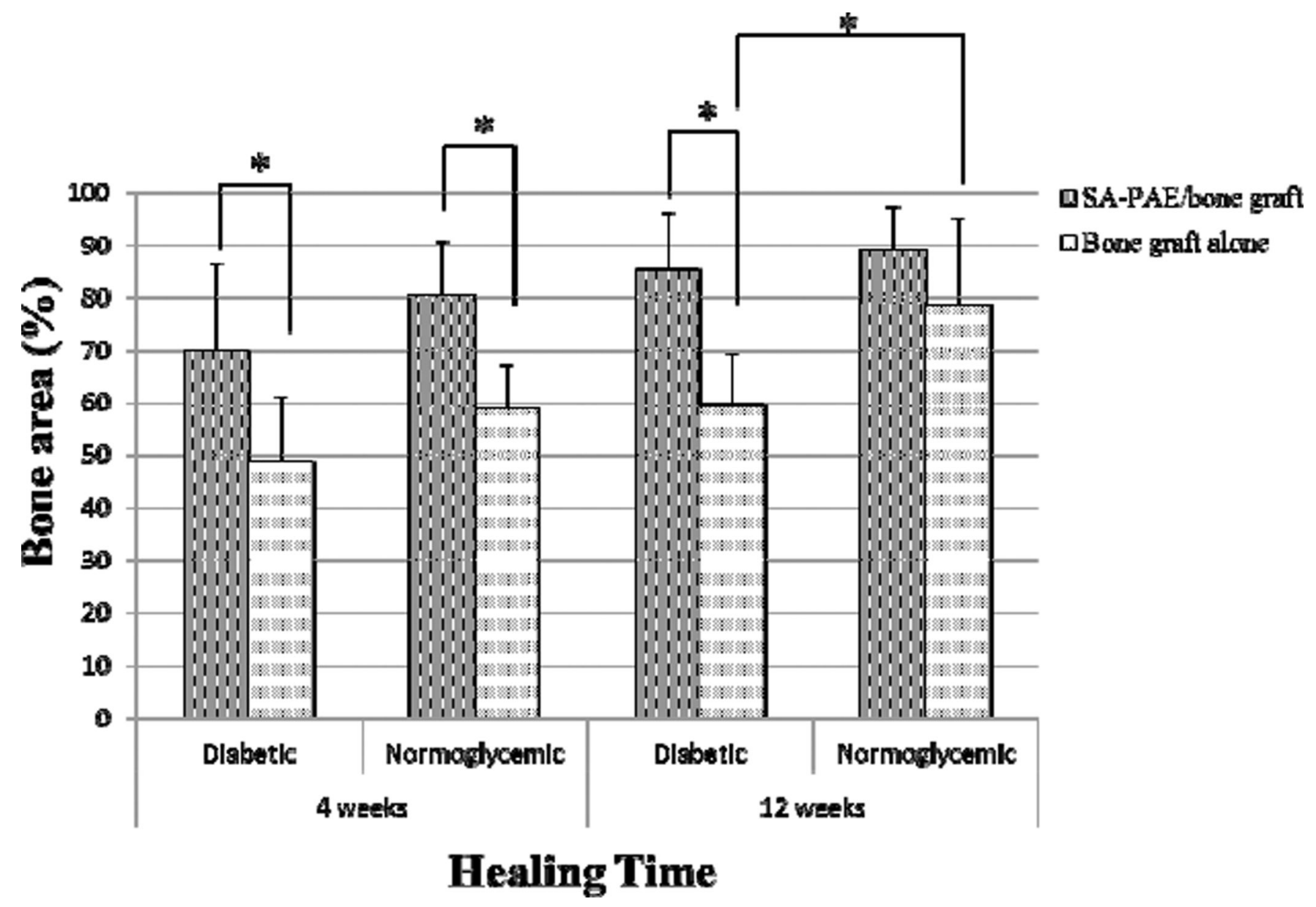

Figure 4.

Quantitative comparison in mineralized bone (new bone and bone graft) within the defect analyzed by micro-CT. Data are presented as mean + standard deviation. $\mathrm{N}=6-7 /$ group. (*p $<0.05)$. 

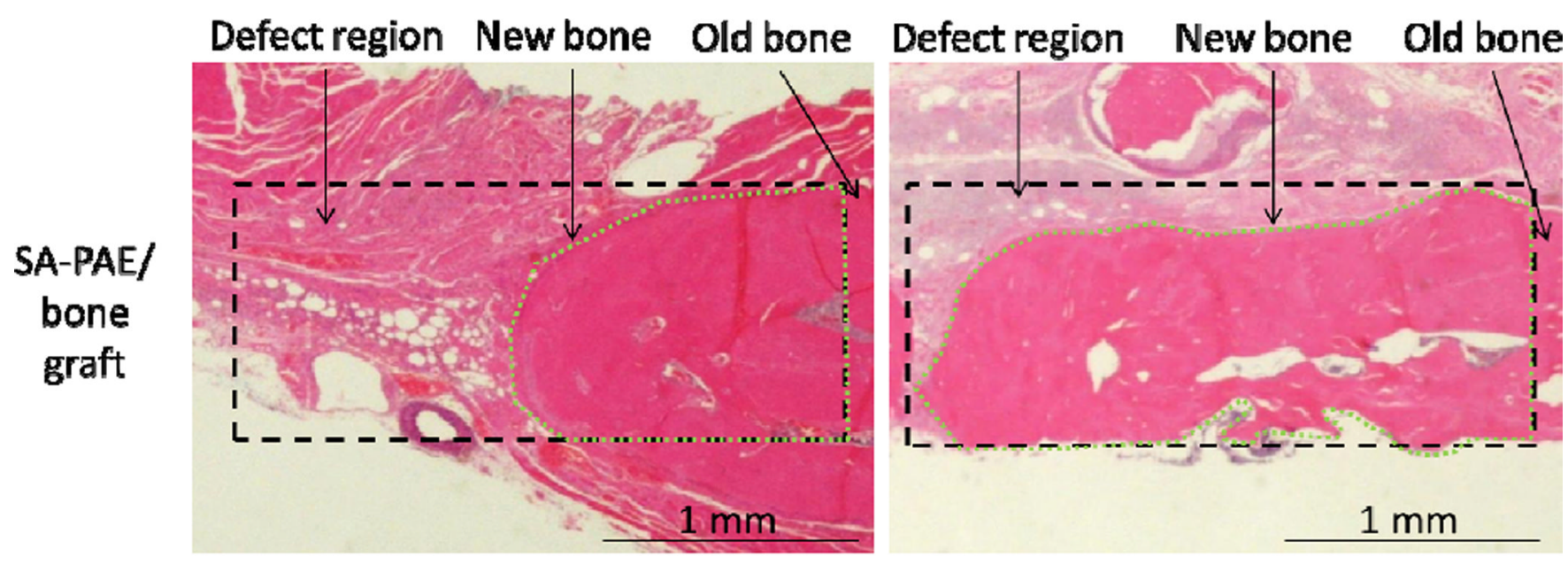

\section{Defect region New bone old bone}

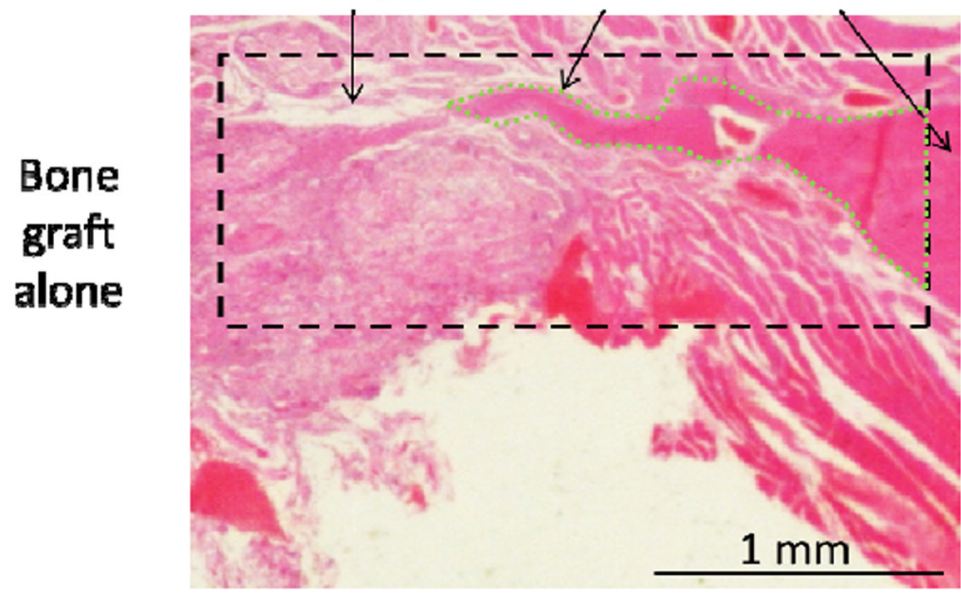

Diabetic
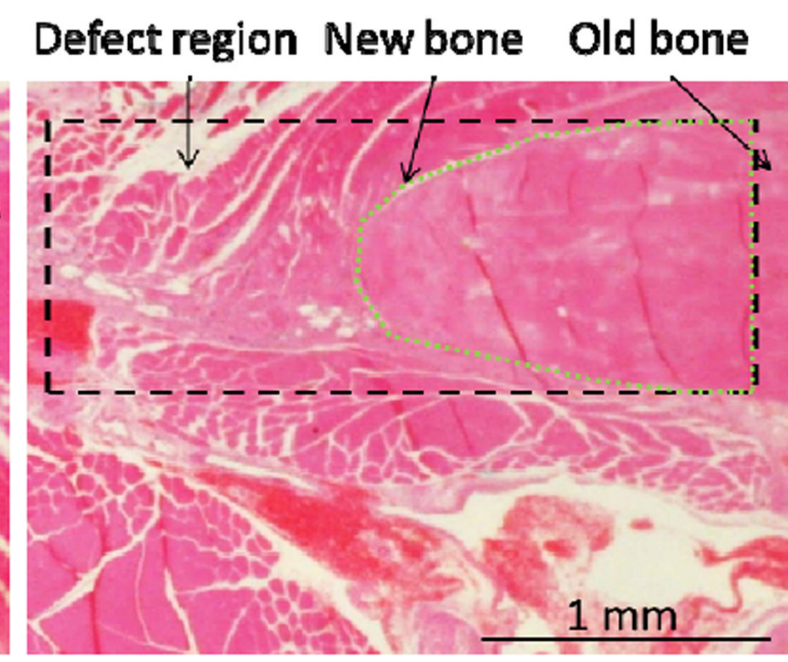

\section{Normoglycemic}

Figure 5.

Representative H\&E staining of one half of the defect region where new bone formation was quantified at 12 -week time point. New bone formed (enclosed by green dotted line) in one half of the defect (enclosed by black dotted line) is marked. Diabetic (A, C) or normoglycemic $(\mathrm{B}, \mathrm{D})$ rats implanted with SA-PAE/bone graft $(\mathrm{A}, \mathrm{B})$ or bone graft alone $(C, D)$ in the $5 \mathrm{~mm}$ diameter critical size defect. $\mathrm{N}=3-4$ /group. 


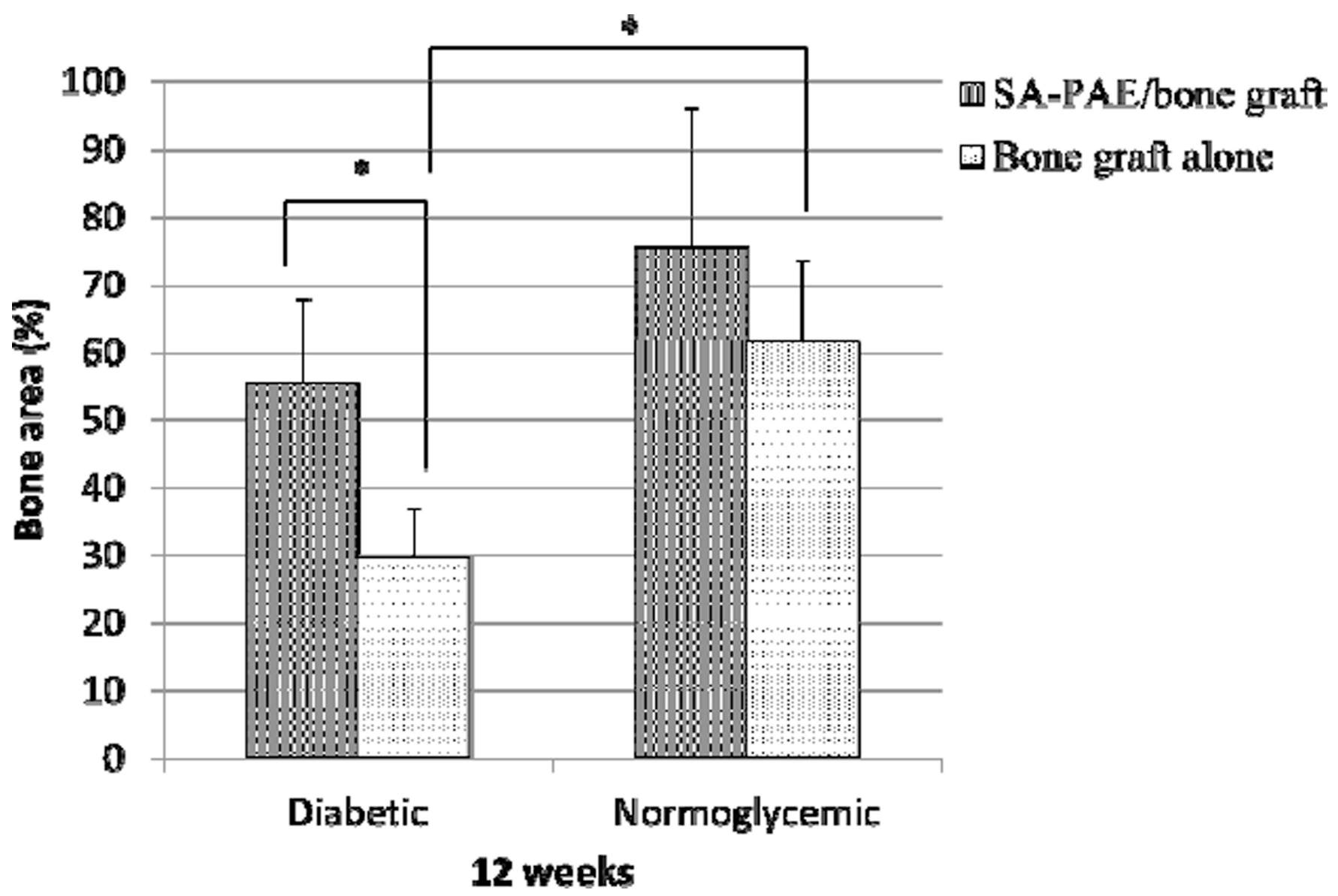

Figure 6.

Histomorphometric comparison of new bone percentage within the defect at 12 weeks. Data are presented as mean + standard deviation $\left(\mathrm{n}=3-4,{ }^{*} p<0.05\right)$. 
Table 1

HbA1c levels in streptozotocin induced diabetes $(n=6)($ mean \pm standard deviation)

\begin{tabular}{|c|c|}
\hline 4 weeks & 12 weeks \\
\hline $11.76 \pm 1.01$ & $10.78 \pm 1.16$ \\
\hline
\end{tabular}

